\title{
Factors associated with infant and adolescent mortality
}

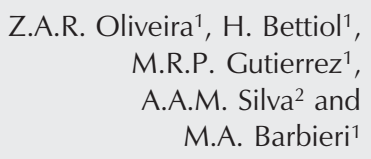

\author{
${ }^{1}$ Departamento de Puericultura e Pediatria, Faculdade de Medicina de Ribeirão Preto, \\ Universidade de São Paulo, Ribeirão Preto, SP, Brasil \\ ${ }^{2}$ Departamento de Saúde Pública, Universidade Federal do Maranhão, São Luís, MA, \\ Brasil
}

\begin{abstract}
Correspondence
H. Bettiol

Departamento de Puericultura e

Pediatria, FMRP, USP

Av. Bandeirantes, 3900

14049-900 Ribeirão Preto, SP

Brasil

Fax: +55-16-3602-2700

E-mail: hbettiol@fmrp.usp.br

Research supported by CNPq.

Publication supported by FAPESP.
\end{abstract}

Received September 18, 2006 Accepted May 18, 2007

\begin{abstract}
Few studies have described factors associated with infant and adolescent mortality since birth. We report here mortality during a 20-year period in a birth cohort from Ribeirão Preto in order to identify birth variables that influenced mortality among infants and children between 10 and 19 years of age, the main causes of death, and the influence of social inequality at birth on death. Mothers were interviewed shortly after delivery. Social, biological and demographic information was collected, and mortality up to 19 years of age was investigated in registry systems. Of the 6748 liveborn singletons born in the municipality from 1978 to 1979,343 died before or when 19 years of age were completed. Most of the cohort mortality (74.9\%) occurred during the first year of life and 19.6\% occurred from 10 to 19 years. Mortality was higher among boys. Preterm birth (hazard ratio, $\mathrm{HR}=7.94)$ and low birth weight $(\mathrm{HR}=10.15)$ were strongly associated with infant mortality. Other risk factors for infant mortality were: maternal age $\geq 35$ years $(\mathrm{HR}=1.74)$, unskilled manual occupation of family head $(\mathrm{HR}=2.47)$, and for adolescent mortality: unskilled manual occupation of family head $(\mathrm{HR}=9.98)$ and male sex $(\mathrm{HR}=$ 6.58). "Perinatal conditions" were the main causes of deaths among infants and "external causes" among adolescents, especially boys. Socioeconomic factors at birth, represented by occupation, influenced adolescent mortality due to external causes, which was higher among boys (7:1). The influence of social inequality at birth on death, measured by occupation, was greater in adolescence than in infancy.
\end{abstract}

Key words

- Infant mortality

- Adolescence

- Causes of death

- External causes

- Socioeconomic factors

- Social inequality

- 20-year Brazilian cohort study

\section{Introduction}

Mortality is conditioned by biological, political and social factors, as well as by culturally defined behaviors and attitudes that historically characterize the stage of development of a country or a region. Among the several factors associated with mortality are maternal age and schooling (1), maternal smoking (2), socioeconomic inequality (3), and medical and social services for pregnant women and for newborns $(4,5)$. Some biological factors are also risk factors for mortality, such as male gender (6), low birth weight and preterm birth $(4,5)$.

In Brazil, general mortality has been decreasing in all age ranges over the last 20 years - especially during the first year of life 
- probably due to public health interventions related to the promotion of breast-feeding, oral rehydration therapy, growth monitoring and immunization, whereas mortality due to physical injuries, whose control has been relegated to a secondary role, has demonstrated an ascending trend (7). If we exclude the first year of life, when affections originating during the perinatal period, intestinal infectious diseases and acute respiratory diseases are among the main causes of mortality (8), physical injuries cause more deaths of children and adolescents than all major diseases taken together. Depending on the age range, 20 to $70 \%$ of all deaths are due to external causes, especially traumatic traffic injuries, drowning, burns, and homicides $(7,9)$.

Little is known about whether socioeconomic differentials in mortality persist through adolescence or if this inequality increases or is reduced over time. West (10) showed that in Britain, in 1991, mortality differentials that were apparent in childhood were virtually absent at 10-14 years of age. More recently, Petrou et al. (11) concluded that in two English counties, Oxfordshire and West Berkshire, from 1979 to 1988, the effect of social class gradient on mortality, while still evident, was somewhat attenuated by the later childhood years. There is no information regarding this issue for Brazil, because data on social variables in mortality files are usually of poor quality.

Due to the scarcity of longitudinal studies in developing countries designed to identify factors which, present at birth, may be associated with mortality during adolescence, in the present investigation, we studied the mortality of a cohort of liveborns over a period of 20 years. The objective was to describe infant and adolescent mortality, to identify among some variables present at birth the ones that represented risk factors for mortality during the first year of life and from 10 to 19 years of age, to identify the major groups of causes of death, and to determine whether social inequality at birth increased the risk factor for mortality in infancy or during adolescence.

\section{Material and Methods}

The study was conducted in Ribeirão Preto, a city located $320 \mathrm{~km}$ northeast of the capital of the State of São Paulo, Brazil, which in 1978 had a population of 318,496 inhabitants, and which is considered to be one of the richest in the country. The economically active population consisted of 136,034 individuals ( $42.7 \%$ of the total population) and the main economic activities were services, commerce goods, wares, and transformation industry, with emphasis on sugar cane and the sugar agroindustry (12).

All 6748 singleton newborns delivered at the 8 maternities in the municipality from June 1, 1978 to March 31, 1979, by mothers living in the municipality participated in the study. The puerperae were interviewed and informed about the objective of the study and gave oral informed consent to participate. The infants were weighed unclothed immediately after birth by trained personnel using a Filizola baby scale with 10 -g precision which was calibrated weekly. The study was approved by the clinical directors of all hospitals involved. Since at the time there was no Research Ethics Committee, ethical questions were discussed with a Legal Medicine professor and it was decided that mothers who did not give their consent, whose doctor did not give permission, who were unwell after delivery, and whose babies were ill or died immediately after delivery would not be interviewed. In these cases, information about mother and baby was obtained from the medical records $(12,13)$.

Starting in June 1999, a survey of the deaths in Ribeirão Preto that had occurred during the 20 years of the study was first carried out using the Death Records as well as the Birth Records (which contain information about death and about the Registry Office where the certificate was issued). 
When the death of an individual born by single delivery in Ribeirão Preto from June 1, 1978 to May 31, 1979 was detected, all the data in the certificate were recorded on a protocol form. The basic cause of death was recorded and classified and grouped according to the groups of causes defined in the 9th Revision of the International Classification of Diseases (ICD-9) (WHO, 1985). This classification was maintained also for all individuals who had died after the adoption of the 10th Revision (1995) to guarantee the homogeneity of information.

A total of 355 death certificates for individuals born during the study period, issued by the civil registries of the municipality from June 1978 to 19 years of age of the participants were located. The birth questionnaires were located for $96.6 \%$ (343/355) of the children. The 12 children without birth questionnaire, although registered as having been born in Ribeirão Preto during the study period, did not necessarily belong to the cohort but had possibly been born in nearby towns and registered in Ribeirão Preto. These children were not considered in the present analysis.

The maternal and social variables included in the analyses and their respective categories were: age in complete years $(<18$, 18 and $19 ; 20$ to 34 , and $\geq 35$ ), mother's marital status (with or without a companion), maternal schooling in years $(<4,4$ to 11 , and $\geq 12$ ), maternal smoking during pregnancy (yes/no, regardless of the number of cigarettes smoked), previous pregnancies (yes/no, with no reference to number, including abortions, stillborns and liveborns), and occupation of family head. The variables related to maternal and newborn medical care included in the analysis were: number of prenatal visits $(0,1$ to 3 , and $\geq 4)$; category of admission (public and private), type of delivery (vaginal; cesarean section), preterm birth (yes if $<37$ weeks of gestation and no for the remaining cases), newborn gender (male, female), low birth weight (yes if $<2500 \mathrm{~g}$ and no otherwise). Gestational age was calculated according to date of the last normal menstrual period. The occupation of the family head was elaborated and adapted by Bettiol et al. (14) based on the model proposed by Olsen and Frische (15) and divided into three categories: non-manual worker, skilled or semiskilled manual worker, and unskilled manual worker or unemployed. In most cases the occupation of the father was used for this classification. When the occupation of the father was not identified or when the mother had no companion, the occupation of the mother was used. The "not known" category was included for all variables, representing unknown information (mothers who did not answer the questionnaire or did not know the answer to a specific question). However, ignored values corresponding to $5 \%$ or less of the total number of children in the age range considered were not included in the analyses. All of these variables were obtained from the birth questionnaire that was answered by the mothers.

A descriptive analysis of the distribution of mortality by age range and by gender (with the respective 95\% confidence intervals, 95\% CI) was carried out and mortality rates were calculated for the major groups of causes of death classified according to the International Statistical Classification of Diseases, Injuries and Causes of Death, 1975 Revision (16) for infants and adolescents. The cumulative mortality rates were calculated by taking as the common denominator for all ages the total number of liveborns in the cohort.

The probabilities of cohort survival were studied with respect to gender and occupation of family head by applying the KaplanMeier survival curves (17). The log-rank test was calculated to compare differences between the survival probabilities according to gender and occupation, with the level of significance set at 0.05 .

In the adjustment for confounding factors associated with the event (death), 
stepwise Cox regression was used with backward elimination of the variables, with the hazard ratio (HR), which is a direct estimate of relative risk, being obtained in the model, as well as the respective 95\% CI (18). The sum of time, in months, during which the individuals of the cohort were exposed to the risk of death ("time at risk") was calculated, taking into consideration that this time differs among persons as the deaths occur.

Table 1. Mortality rates for liveborn singletons delivered at hospitals from the 1978/79 Ribeirão Preto birth cohort.

\begin{tabular}{lccrc}
\hline Mortality & Age ranges & $\mathrm{N}(\%)$ & $\mathrm{MR}$ & $95 \% \mathrm{Cl}$ \\
\hline Early neonatal & $0 \vdash 7$ days & $143(41.7 \%)$ & 21.2 & 17.9 to 24.9 \\
Late neonatal & $7 \vdash 28$ days & $21(6.1 \%)$ & 3.1 & 1.9 to 4.8 \\
Neonatal & $0 \vdash 28$ days & $164(47.8 \%)$ & 24.3 & 20.8 to 28.3 \\
Post-neonatal & $28 \vdash 365$ days & $93(27.1 \%)$ & 13.8 & 11.1 to 16.9 \\
Infant & $0 \vdash 365$ days & $257(74.9 \%)$ & 38.1 & 33.6 to 42.9 \\
Preschooler & $1 \vdash 5$ years & $13(3.8 \%)$ & 1.9 & 1.1 to 3.3 \\
Schoolchild & $5 \vdash 10$ years & $6(1.7 \%)$ & 0.9 & 0.3 to 1.9 \\
Early adolescence & $10 \vdash 15$ years & $13(3.8 \%)$ & 1.9 & 1.1 to 3.3 \\
Final adolescence & $15 \vdash 20$ years & $54(15.8 \%)$ & 8.0 & 6.1 to 10.4 \\
Total & $0 \vdash 20$ years & $343(100 \%)$ & 50.8 & 45.7 to 56.3 \\
\end{tabular}

$\mathrm{N}=$ Number of observations with percent in parentheses; MR = mortality rate per 1000 cohort liveborns; $95 \% \mathrm{Cl}=95 \%$ confidence interval.

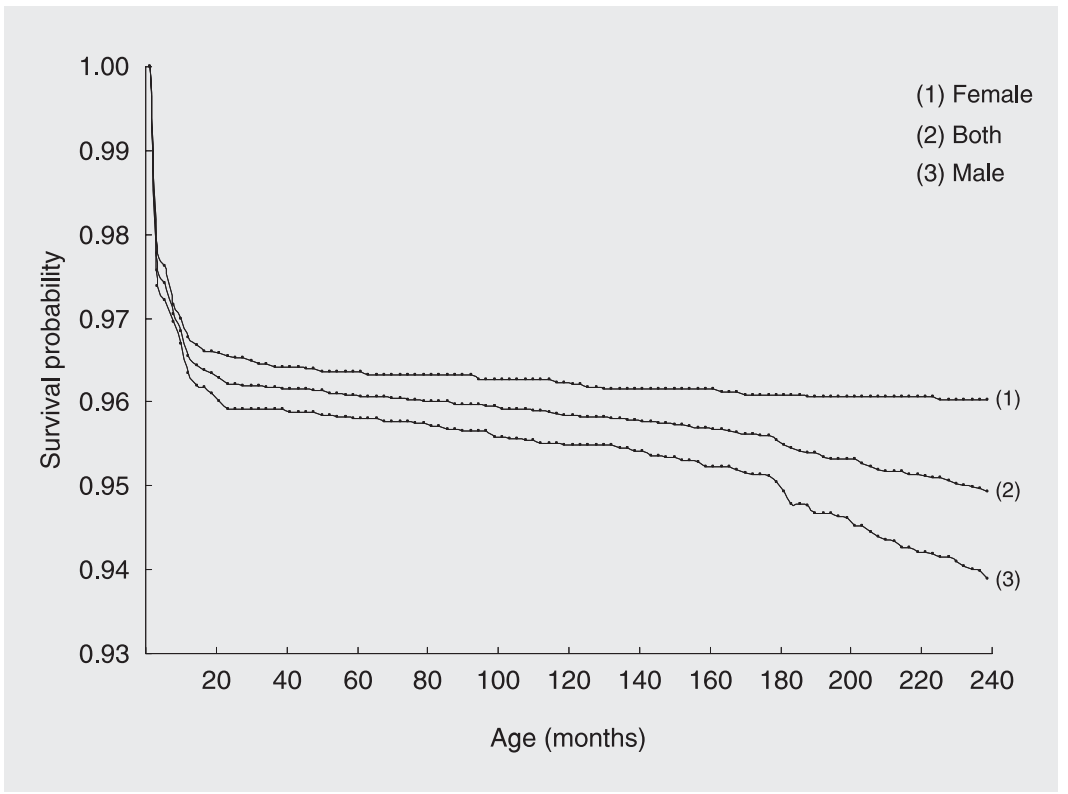

Figure 1. Survival probability (based on Ref. 17) of the 1978/1979 Ribeirão Preto birth cohort according to age. Note: the ordinate does not start at 0 .
Thus, the deaths that occurred from birth to the ninth year of life were excluded from the denominator for the calculation of the mortality rate and HR for the 10- to 19-year age range. The mortality rates were calculated by dividing the number of deaths in each age range by the sum of the time of exposure to the risk of death.

In the adjusted analyses, the following independent variables were considered for infants: maternal age, marital status, schooling, smoking habit, previous pregnancies, occupation of family head, number of prenatal visits, category of admission to the hospital, and type of delivery. Birth weight and gestational age were not included because they were considered to be intervening variables. For the 10- to 19-year range, gender, maternal smoking habit and occupation of family head were included in the model. The significance level was set at 0.05 .

The statistical analyses were carried out with the help of the Stata 8.0 software.

\section{Results}

Most of the deaths in the cohort (74.9\%) occurred during the first year of life. The most important component of infant mortality (IM) was neonatal (deaths during the first 27 days of life, $41.7 \%$ ), followed by a post-neonatal component (deaths from 28 days of life to less than 1 year, $27.1 \%)$. The preschool (1-4 years), schoolchild (5-9 years) and early adolescence (10-14 years) components showed low mortality, in contrast to the final phase of adolescence (15-19 years) when the mortality rate was about 4 to 9 times higher than during the previous ages (Table 1).

Survival probabilities differed according to gender. The Kaplan-Meier method showed greater falls in the probabilities of survival among boys, with an abrupt inflection of the curve starting at 180 months or 15 years $(\mathrm{P}$ value for the log-rank test $<0.001$; Figure 1 ). Survival probabilities also differed according to father's occupation. It was evident 
that the greatest falls in the probability of survival occurred for children of fathers with an unskilled occupation or unemployed, especially starting at 180 months or 15 years of age, whereas the lowest falls occurred for children of fathers with a non-manual occupation (P value for the log-rank test $<0.001$; Figure 2).

Non-adjusted analysis of some birth factors showed that previous pregnancies $(\mathrm{P}=$ $0.122)$, type of delivery $(\mathrm{P}=0.404)$ and newborn gender $(\mathrm{P}=0.199)$ were not associated with IM. The risk of dying during the first year of life was higher for children of mothers aged $\geq 35$ years $(\mathrm{HR}=1.78,95 \% \mathrm{CI}$ $=1.23$ to 2.57$)$ and $<18$ years $(\mathrm{HR}=2.12$, $95 \% \mathrm{CI}=1.39$ to 3.25 ), with no companion $(\mathrm{HR}=2.14,95 \% \mathrm{CI}=1.49$ to 3.08$)$, with 4 to 11 years of schooling $(\mathrm{HR}=2.33,95 \% \mathrm{CI}=$ 1.19 to 4.57$)$ and $<4$ years $(\mathrm{HR}=3.10$, $95 \% \mathrm{CI}=1.54$ to 6.21 ), who were smokers $(\mathrm{HR}=1.18,95 \% \mathrm{CI}=0.86$ to 1.61$)$, who attended 1 to 3 prenatal visits $(\mathrm{HR}=1.69$, $95 \% \mathrm{CI}=1.16$ to 2.46 ) or who did not receive prenatal care $(\mathrm{HR}=2.57,95 \% \mathrm{CI}=$ 1.71 to 3.85 ), who were admitted to public hospitals $(\mathrm{HR}=1.92,95 \% \mathrm{CI}=1.12$ to 3.30$)$, with a family head having a skilled/semiskilled manual occupation $(\mathrm{HR}=2.23$, $95 \% \mathrm{CI}=1.37$ to 3.65 ) or an unskilled manual occupation/unemployed $(\mathrm{HR}=2.59,95 \% \mathrm{CI}$ $=1.53$ to 4.39$)$, and for preterm $(\mathrm{HR}=7.94$, $95 \% \mathrm{CI}=5.81$ to 10.85 ) and low birth weight $(\mathrm{HR}=10.15,95 \% \mathrm{CI}=7.87$ to 13.10$)$ infants.

After adjustment, the following variables were associated with a higher risk of death during the first year of life: maternal age $\geq 35$ years $(\mathrm{HR}=1.74)$, skilled/semiskilled manual occupation $(\mathrm{HR}=2.08)$ and unskilled manual occupation of the family head or unemployed $(\mathrm{HR}=2.47$; Table 2).

In non-adjusted analysis, maternal smoking was not associated with mortality in the 10 - to 19 -year range $(\mathrm{P}=0.570)$, whereas children of unskilled manual workers or unemployed fathers had a higher risk of death
$(\mathrm{HR}=8.15,95 \% \mathrm{CI}=2.49$ to $27.71 ; \mathrm{P}<$ 0.001 ), as also did individuals of male gen$\operatorname{der}(\mathrm{HR}=7.04,95 \% \mathrm{CI}=3.37$ to $14.7 ; \mathrm{P}<$ 0.001 ; data not shown in tables). After adjustment, the following variables continued to be associated with a higher risk of death during adolescence: belonging to a family whose head had a skilled or semi-skilled manual occupation $(\mathrm{HR}=3.77)$ or an unskilled manual occupation, or was unemployed $(\mathrm{HR}=9.98)$, and male gender $(\mathrm{HR}=$ 6.58; Table 2), with the risk being strongly increased for manual occupations and males when compared to the unadjusted model.

Regarding mortality according to group of causes, based on the causes of death (ICD9) (16) from birth to 19 years of age, the group "Conditions Originating in the Perinatal Period" (28.9\%) comprised the most frequent causes, followed by "Infectious and Parasitic Diseases" and "External Causes" $(17.5 \%)$ and "Diseases of the Respiratory System" (16.9\%). Taken together, these four groups accounted for $80.8 \%$ of the mortality rate of the cohort. Whereas the major group of causes of death was "Conditions Origi-

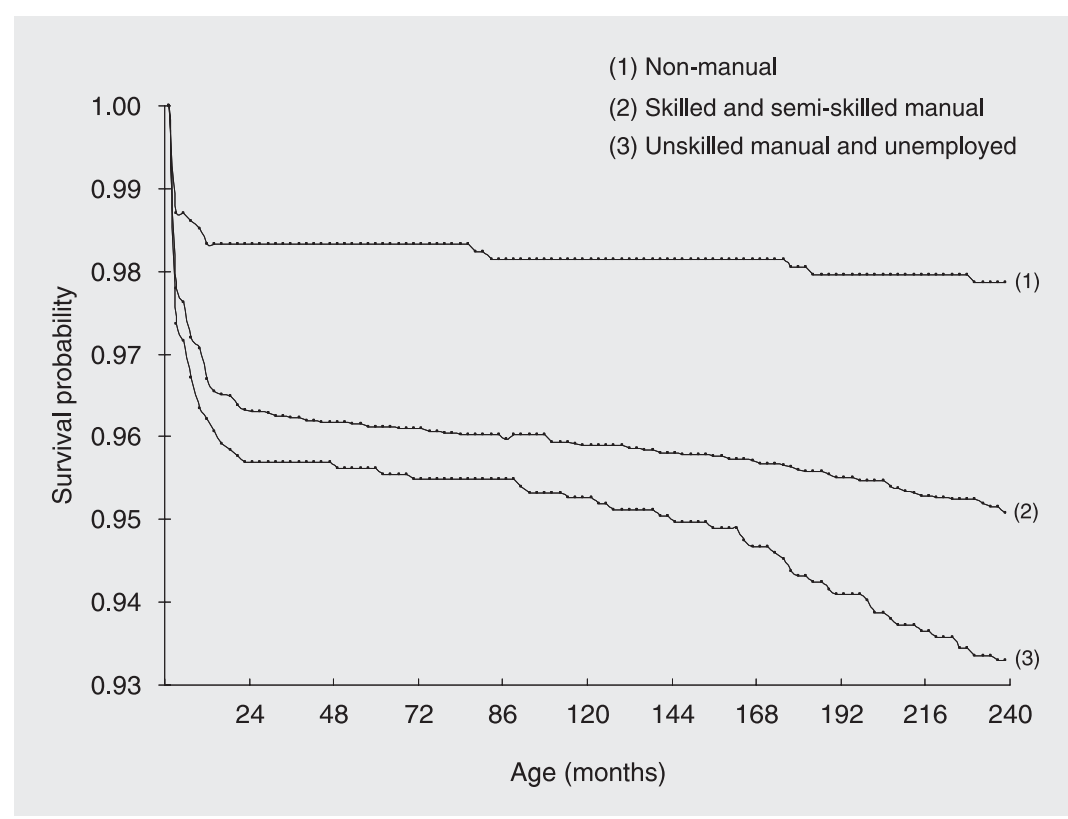

Figure 2. Survival probability (based on Ref. 17) of the 1978/1979 Ribeirão Preto birth cohort according to parental occupation. Note: the ordinate does not start at 0 . 
nating in the Perinatal Period" for infants (38.5\%), "External Causes" was the major group for the 10- to 19 -year range $(79.0 \%$; Table 3), with a coefficient 3.7 times higher than the sum of the coefficients of all the other causes of death in the same age range. Of the 13 deaths that occurred in the 10- to 14-year range, $6(46.2 \%)$ were due to external causes, all of them due to traffic accidents. Of these, $4(66.7 \%)$ were due to being run over by a car and the other 2 were due to unspecified causes. In the 15- to 19-year range, 47 of the total of 54 deaths $(87 \%)$ were due to external causes, with the following specific causes: 19 due to firearms and 19 due to penetrating, cutting or perforating objects, with each subgroup accounting for $35.2 \%$ of the total, $6(14 \%)$ were due to unspecified traffic accidents, 1 was due to drowning, and 1 to lightning.

\section{Discussion}

The present study shows that the influence of social inequality at birth on death was about three times greater during adoles-

Table 2. Adjusted analysis of birth risk factors for infant and adolescent mortality of the 1978/79 Ribeirão Preto birth cohort.

\begin{tabular}{|c|c|c|c|c|c|c|}
\hline Categories & Total & Deceased & Time & Rate & $\mathrm{HR}$ & $95 \% \mathrm{Cl}$ \\
\hline \multicolumn{7}{|l|}{ Younger than 1 year } \\
\hline \multicolumn{7}{|l|}{ Maternal age ${ }^{*}$ (years) } \\
\hline 20 to 34 & 5175 & 176 & $1,195,015$ & 14.73 & 1.00 & - \\
\hline 18 and 19 & 608 & 20 & 140,754 & 14.21 & 0.87 & 0.53 to 1.42 \\
\hline$\geq 35$ & 566 & 34 & 127,347 & 26.70 & 1.74 & 1.14 to 2.66 \\
\hline$<18$ & 336 & 24 & 74,771 & 32.10 & 1.45 & 0.91 to 2.29 \\
\hline Not known & 63 & 3 & - & - & - & - \\
\hline \multicolumn{7}{|l|}{ Maternal smoking ${ }^{*}$} \\
\hline No & 4626 & 120 & $1,077,789.5$ & 11.13 & 1.00 & - \\
\hline Yes & 1871 & 57 & $433,480.5$ & 13.15 & 1.19 & 0.85 to 1.64 \\
\hline Ignored & 251 & 80 & - & - & 53.59 & 37.11 to 77.40 \\
\hline \multicolumn{7}{|l|}{ Occupation of family head* } \\
\hline Non-manual & 1076 & 18 & $253,561.0$ & 7.10 & 1.00 & - \\
\hline Skilled/semiskilled manual & 3846 & 143 & $885,359.0$ & 16.15 & 2.08 & 1.24 to 3.51 \\
\hline Unskilled manual/unemployed & 1372 & 59 & $313,463.0$ & 18.82 & 2.47 & 1.41 to 4.34 \\
\hline Not known & 454 & 37 & $99,908.5$ & 37.03 & 2.46 & 1.29 to 4.72 \\
\hline \multicolumn{7}{|l|}{ Newborn gender ${ }^{\star *}$} \\
\hline Female & 3272 & 114 & $755,960.5$ & 15.08 & 1.00 & - \\
\hline Male & 3473 & 142 & $795,850.5$ & 17.84 & 1.27 & 0.97 to 1.65 \\
\hline Total & 6748 & 257 & $1,552,291.5$ & 16.56 & - & - \\
\hline \multicolumn{7}{|l|}{ Adolescent } \\
\hline \multicolumn{7}{|l|}{ Occupation of family head* } \\
\hline Non-manual & 1056 & 3 & 253,377 & 1.18 & 1.00 & - \\
\hline Skilled/semiskilled manual & 3690 & 34 & 884,523 & 3.84 & 3.77 & 1.15 to 12.33 \\
\hline Unskilled manual/unemployed & 1310 & 30 & 313,241 & 9.58 & 9.98 & 3.05 to 32.70 \\
\hline Not known & 416 & 0 & - & - & - & - \\
\hline \multicolumn{7}{|l|}{ Newborn gender* } \\
\hline Female & 3152 & 8 & 755,523 & 1.06 & 1.00 & - \\
\hline Male & 3320 & 59 & 794,978 & 7.42 & 6.58 & 3.14 to 13.80 \\
\hline Total & 6472 & 67 & $1,550,981$ & 4.32 & - & - \\
\hline
\end{tabular}

Time = sum of the time, in months, at risk for the children in each category; $\mathrm{HR}=$ hazard ratio; $95 \% \mathrm{Cl}=95 \%$ confidence interval. The not known values for the variables that corresponded to $5 \%$ or less of the total number of children ( $N=6748$ for the first year of life and $N=6472$ for the 10- to 19-year range) were not included in the analysis.

${ }^{*} P<0.05$ for one category of the variable statistically different from others ${ }^{*} \mathrm{P}=0.086$ (stepwise Cox regression analysis). 
cence $(H R=8.15)$ than during infancy (HR $=2.59$ ). It was shown that, whereas the risk factors for mortality during the first year of life were maternal age of 35 years or more and manual occupation of the family head, the main risk factor for mortality during adolescence was related to social position at birth, with children of families whose heads held unskilled manual jobs or were unemployed having the highest risk of death (HR $=9.98)$, along with male gender $(\mathrm{HR}=6.58)$.

The present study is the first of its kind in Brazil by following up liveborns of a cohort for 20 years. Some cohort studies have revealed the late effects on infancy and adolescence of nutritional deprivation during intrauterine life and during the first months of life (19). However, few studies are available regarding the association of conditions present at birth with mortality during adolescence and adulthood (20). The follow-up of children in a cohort study is unusual in developing countries due to the countless difficulties involved in maintaining contact with people for a prolonged period of time (21).

It was possible to locate four cohort from studies in developing countries, from birth to 12 years of age or more, among them the present study conducted in Ribeirão Preto, Brazil, from June 1978 to May 1979 (12), a study conducted in Pelotas, RS, Brazil, with the participation of 6011 liveborns in 1982 (22), a study conducted in Cebu, the Philippines, with the participation of 3080 singleton liveborns from May 1983 to April 1984 (23), and a study conducted in Johannesburg, South Africa, with the participation of 2454 singleton liveborns from April to June 1990 (24). Although some cohort studies reported mortality $(5,22)$, few continued follow-up beyond adolescence $(25,26)$.

The marked decline in survival probability that occurred during the first year of life and from 10 to 19 years of age led us to concentrate the present study on these two age ranges. The infant mortality rate (IMR; 38.1 deaths/1000 liveborns) was close to that observed in a similar cohort from Pelotas, RS, in 1982, 38.8/1000 liveborns (22). However, when the present cohort was compared with the 1994 one (16.9/1000 liveborns) using a similar methodology (27), a 55.6\% fall in IMR was observed in Ribeirão Preto during this 15 -year period.

Table 3. Mortality rates by group of causes (ICD-9) of infants and adolescents from the 1978/79 Ribeirão Preto birth cohort.

\begin{tabular}{|c|c|c|c|c|c|}
\hline \multirow[t]{2}{*}{ Group } & \multirow[t]{2}{*}{ Classification } & \multicolumn{2}{|c|}{ Infants ( 0 to $<1$ year) } & \multicolumn{2}{|c|}{ Adolescents (10 to 19 years) } \\
\hline & & N. of deaths $(\%)$ & MR & N. of deaths (\%) & MR \\
\hline I & Infectious and parasitic diseases & $55(21.4 \%)$ & 8.2 & - & - \\
\hline II & Neoplasms & - & - & $4(6.0 \%)$ & 0.6 \\
\hline III & Endocrine, nutritional and metabolic diseases & $10(3.9 \%)$ & 1.5 & $3(4.5 \%)$ & 0.5 \\
\hline VI & Diseases of the nervous system & $3(1.2 \%)$ & 0.4 & $3(4.5 \%)$ & 0.5 \\
\hline VII & Diseases of the circulatory system & $2(0.8 \%)$ & 0.3 & $1(1.5 \%)$ & 0.1 \\
\hline VIII & Diseases of the respiratory system & $52(20.2 \%)$ & 7.7 & $3(4.5 \%)$ & 0.5 \\
\hline IX & Diseases of the digestive system & $8(3.0 \%)$ & 1.2 & - & - \\
\hline $\mathrm{x}$ & Diseases of the genitourinary system & $2(0.8 \%)$ & 0.3 & - & - \\
\hline XI & Complications of pregnancy, childbirth, and the puerperium & $2(0.8 \%)$ & 0.3 & - & - \\
\hline XIV & Congenital abnormalities & $19(7.4 \%)$ & 2.8 & - & - \\
\hline $\mathrm{XV}$ & Conditions originating in the perinatal period & $99(38.5 \%)$ & 14.7 & - & - \\
\hline XVI & Symptoms, signs and ill-defined conditions & $1(0.4 \%)$ & 0.1 & - & - \\
\hline \multirow[t]{3}{*}{ XVII } & Injury and poisoning (external causes) & $1(0.4 \%)$ & 0.1 & $53(79.0 \%)$ & 8.2 \\
\hline & Not known & $3(1.2 \%)$ & 0.4 & - & - \\
\hline & Total & $257(100.0 \%)$ & 38.0 & $67(100.0 \%)$ & 10.4 \\
\hline
\end{tabular}

MR = Mortality rate per 1000 cohort liveborns. 
In contrast, neonatal mortality $(24.3 / 1000$ liveborns), which is more associated with the quality of medical care during pregnancy and at delivery and birth, was higher than that for Pelotas (21.5/1000 liveborns), whereas post-neonatal mortality (13.8/1000 liveborns), more related to primary care, was lower (17.3/1000 liveborns) (22).

In the Inter-American Investigation of Mortality in Childhood (28), which included 15 projects in 24 areas in the Americas, among them Ribeirão Preto in 1968/70, $78.6 \%$ of the deaths occurred during the first year of life, $36.1 \%$ during the neonatal period and $42.5 \%$ during the post-neonatal period. In Ribeirão Preto the IMR was 43.0/ 1000 liveborns (24/1000 liveborns for the neonatal IMR and 19/1000 for the postneonatal IMR), showing a fall in IMR at the expense of the post-neonatal component. In Brazil, official data regarding mortality by main group of causes of death in the 0- to 19year age range obtained in 1979 showed that the perinatal causes continued to be the most frequent when compared to 1995 data, whereas external causes went from fourth to second place, replacing infectious and parasitic diseases (7). Although there was a reduction of IMR in Ribeirão Preto between the Inter-American Investigation (28) and the current study, the relative contributions of perinatal, infectious and congenital anomaly causes remained fairly similar.

In the present study, non-adjusted analysis showed once again that birth weight and gestational age were the two variables with the greatest magnitude of association with IM $(4,27)$, with preterm newborns presenting an almost 8 -fold higher probability of dying during the first year of life compared to term newborns and low birth weight newborns presenting a 10-fold higher risk compared to newborns of adequate weight.

Maternal smoking has been associated with infant mortality (29-31), showing a doseresponse effect (29) and an increasing adverse effect with increasing gestational age, suggesting a cumulative effect of smoking on mortality (30). In addition, the risk of death of infants whose mothers stopped smoking during pregnancy is comparable to the risk of death of infants born to mothers who do not smoke (31). In the present study, in the adjusted analysis the "not known" category of maternal smoking represented a risk factor for IM. Since the mothers whose children were in poor health condition or died immediately after delivery were not interviewed, it was not possible to determine the smoking status of these mothers during pregnancy. Since 65 of the 80 deaths that occurred among children born to mothers whose smoking condition was unknown occurred during the first month of life, we may speculate that an important portion of the children included in this group were born to smoking mothers.

The IMR for children born to older mothers and mothers belonging to the skilled manual worker class were higher in adjusted analysis, a result similar to that reported in other studies (27,32). English children born in the unskilled worker class presented a higher risk of death during the first year of life, with the risk persisting along the first 10 years of life (11).

In the present study, occupation of family head was the variable with the highest HR of death in the 10- to 19-year range, as confirmed by the statistically significant distance $(\mathrm{P}<0.001)$ between the survival probability curves for adolescents whose fathers had a non-manual occupation and adolescents whose fathers had an unskilled manual occupation or were unemployed. The latter had a 10-fold higher probability of dying during adolescence. Osler et al. (26) observed that, even after adjustment for variables such as birth weight and cognitive function, the inverse association between father's social class at the time of the infant's birth and mortality among young adult men (15 to 34 years) was slightly attenuated but continued to be present. 
In the 15- to 19-year subgroup, the deaths predominated among boys; $87 \%$ were due to external causes, with $70.4 \%$ being due to violence, in agreement with other studies (33-38). Starting in the 1960 decade, in Brazil infectious and parasitic diseases gave way to external causes represented by traffic accidents and homicides as the main cause of mortality in some age ranges. From 1930 to 1991 , the mortality rates due to external causes for both genders increased by $363 \%$ in Rio de Janeiro and by $193 \%$ in São Paulo, with a wide variation between male and female gender reaching, in the case of homicides, a 22:1 and 16:1 ratio in Rio de Janeiro and São Paulo, respectively (39).

The perspective for the future, as stated by Minayo (33), is prevention since "most violent events and traumatic injuries are not accidental, are not fatalities, are not lack of luck: they can be confronted, prevented and avoided".

When the HR values for the unskilled manual occupation/unemployed category of the family head were compared between the first year of life $(2.47,95 \% \mathrm{CI}=1.41$ to 4.34$)$ and the 10 - to 19 -year range $(9.98,95 \% \mathrm{CI}=$ 3.05 to 32.70 ) it could be seen that, even though mortality was higher during the first year of life, the risk of death related to social inequality at birth was higher in adolescence than in infancy. Whereas mortality during the first year of life was more directly linked to differences in the quality of and access to perinatal care, in adolescence it mainly occurred due to social inequality. Inequalities in mortality being very much higher in adolescence than in infancy are in contrast to what has been observed in Britain, where the social gradient tended to be attenuated over the years $(10,11)$. Our evidence indicates a strong link between socioeconomic disadvantage at birth and higher mortality due to external causes in late adolescence, possibly reflecting huge differences in social environment and access to safety devices in homes and vehicles between the social classes
(11). This also suggests strong differences in exposure to firearms and blade weapons between social classes in Brazil.

Some death certificates did not contain death information regarding the circumstances of the events (basic cause) that produced it, but only the type of wound (associated cause). When the basic cause of death (type of accident/violence) is not specified in the death certificate, there may be important changes in the patterns of mortality due to external causes, as shown by Souza (34) in a study of the variation in mortality rate due to homicides in Rio de Janeiro from 1980 to 1989: when deaths due to injuries of ignored intentionality were not included there was a $35.8 \%$ fall in the homicide rate. However, when deaths due to firearms were included, there was a $94.2 \%$ increase, emphasizing the importance of a correct filling of death certificates.

The limitation of the present study was the difficulty in collecting indirect data, especially regarding the location of the death certificates of children who had moved to other towns. This may possibly be one of the reasons explaining the small number of deaths observed between 1 and 9 years of age despite the existence of Law No. 6015 that has been regulating the obligatory notification of Public Records since December 31, 1973. This fact may have affected less the data regarding the adolescents because of improved information exchange among the civil registries since the mid 1980's. Faulty filling of some death certificates, which did not contain information about the basic cause of death, motivated the use of a classification according to group of causes of death (ICD-9).

The present investigation is important by permitting the study of survival of children in the Ribeirão Preto birth cohort for a long period of 20 years and the identification of the variables that, being present at birth, represented risk factors for mortality in the first year of life and from 10 to 19 years of 
age. The importance of the identification of specific causes of death due to external causes should be emphasized since it is of help for the planning of preventive strategies that could protect lives that are currently threatened. The most relevant finding of the present study was the association between occupation of the family head at the birth of the child and mortality during adolescence that, despite the temporal distance, represented a strongly significant risk factor even after a period of nearly 20 years. Although social inequality at birth affected death at the two time points analyzed, its effect was greater during adolescence, showing that social support is needed throughout life for young individuals in Brazil.

\section{References}

1. Nordström M, Cnattingius S, Haglund B. Social differences in Swedish infant mortality by cause of death, 1983 to 1986. Am J Public Health 1993; 83: 26-30.

2. Kleinman JC, Pierre MB Jr, Madans JH, Land GH, Schramm WF. The effects of maternal smoking on fetal and infant mortality. Am J Epidemiol 1988; 127: 274-282.

3. Goldani MZ, Barbieri MA, Bettiol H, Barbieri MR, Tomkins A. Infant mortality rates according to socioeconomic status in a Brazilian city. Rev Saúde Pública 2001; 35: 256-261.

4. Erickson JD, Bjerkedal T. Fetal and infant mortality in Norway and the United States. JAMA 1982; 247: 987-991.

5. Racine AD, Joyce TJ, Li W, Chiasson MA. Recent declines in New York City infant mortality rates. Pediatrics 1998; 101: 682-688.

6. Khoury MJ, Erickson JD, Adams MJ Jr. Trends in postneonatal mortality in the United States. 1962 through 1978. JAMA 1984; 252 : 367-372.

7. SIM. Sistema de Informações sobre Mortalidade. http://tabnet. datasus.gov.br. Accessed April 30, 2003.

8. Szwarcwald CL, de Castilho EA. Estimates of infant mortality in Brazil in the 80's: a proposal for a methodological procedure. Rev Saúde Pública 1995; 29: 451-462.

9. Organización Panamericana de la Salud (OPAS). La salud en las Américas. Washington: Oficina Sanitária Panamericana; Oficina Regional de la Organización Mundial de la Salud. Publicación Científica y Técnica No. 587; 2002.

10. West $P$. Health inequalities in the early years: is there equalisation in youth? Soc Sci Med 1997; 44: 833-858.

11. Petrou S, Kupek E, Hockley C, Goldacre M. Social class inequalities in childhood mortality and morbidity in an English population. Paediatr Perinat Epidemiol 2006; 20: 14-23.

12. Barbieri MA, Gomes UA, Barros-Filho AA, Bettiol H, Almeida LEA, Silva AAM. Saúde perinatal em Ribeirão Preto, SP, Brasil: a questão do método. Cad Saúde Pública 1989; 5: 376-387.

13. Cardoso VC, Simões VMF, Barbieri MA, Silva AAM, Bettiol H, Alves MTSSB, et al. Profile of three Brazilian birth cohort studies in Ribeirão Preto, SP and São Luís, MA. Braz J Med Biol Res 2007; 40: 1165-1176.

14. Bettiol H, Rona RJ, Chinn S, Goldani M, Barbieri MA. Factors associated with preterm births in southeast Brazil: a comparison of two birth cohorts born 15 years apart. Paediatr Perinat Epidemiol 2000; 14: 30-38.

15. Olsen J, Frische G. Social differences in reproductive health. A study on birth weight, stillbirths and congenital malformations in
Denmark. Scand J Soc Med 1993; 21: 90-97.

16. OMS, Organização Mundial da Saúde. Classificação estatística internacional de doenças, lesões e causas de óbito. Revisão 1975. São Paulo: Centro da OMS para Classificação de Doenças em Português; 1985.

17. Bustamante-Teixeira MT, Faerstein E, Latorre MR. Survival analysis techniques. Cad Saúde Pública 2002; 18: 579-594.

18. Cox DR. Regression models and life tables. J Roy Stat Soc B 1972; 34: $187-220$.

19. Kannisto V, Christensen K, Vaupel JW. No increased mortality in later life for cohorts born during famine. Am J Epidemiol 1997; 145: 987-994.

20. Elo IT, Preston SH. Effects of early-life conditions on adult mortality: a review. Popul Index 1992; 58: 186-212.

21. Seager JR, De Wet T. Establishing large panel studies in developing countries: the importance of the 'Young Lives' pilot phase. http:// www.younglives.org.uk. Accessed March 12, 2004.

22. Barros FC, Victora CG, Vaughan JP. Causes of perinatal mortality in Pelotas, RS (Brazil). Use of a simplified classification. Rev Saúde Pública 1987; 21: 310-316.

23. Adair LS. Low birth weight and intrauterine growth retardation in Filipino infants. Pediatrics 1989; 84: 613-622.

24. Richter LM, Yach D, Cameron N, Griesel RD, de Wet T. Enrolment into birth to ten (BTT): population and sample characteristics. Paediatr Perinat Epidemiol 1995; 9: 109-120.

25. Andersen AM, Osler M. Birth dimensions, parental mortality, and mortality in early adult age: a cohort study of Danish men born in 1953. Int J Epidemiol 2004; 33: 92-99.

26. Osler M, Andersen AMN, Due P, Lund R, Damsgaard MT, Hostein BR. Socioeconomic position in early life, birth weight, childhood cognitive function, and adult mortality. A longitudinal study of Danish men born in 1953. J Epidemiol Commun H 2003; 57: 681-686.

27. Goldani MZ, Barbieri MA, Rona RJ, da Silva AA, Bettiol H. Increasing pre-term and low-birth-weight rates over time and their impact on infant mortality in south-east Brazil. J Biosoc Sci 2004; 36: 177-188.

28. Puffer RR, Serrano CV. Patterns of mortality in childhood. The interAmerican investigation of mortality in childhood. Washington: PanAmerican Health Organization. Scientific Publication 262; 1973.

29. Salihu HM, Aliyu MH, Pierre-Louis BJ, Alexander GR. Levels of excess infant deaths attributable to maternal smoking during pregnancy in the United States. Matern Child Health J 2003; 7: 219-227.

30. Wisborg K, Kesmodel U, Henriksen TB, Olsen SF, Secher NJ. Exposure to tobacco smoke in utero and the risk of stillbirth and 
death in the first year of life. Am J Epidemiol 2001; 154: 322-327.

31. Wilcox AJ. Birth weight and perinatal mortality: the effect of maternal smoking. Am J Epidemiol 1993; 137: 1098-1104.

32. Menezes AM, Barros FC, Victora CG, Tomasi E, Halpern R, Oliveira AL. Risk factors for perinatal mortality in Pelotas, a southern city of Brazil, 1993. Rev Saúde Pública 1998; 32: 209-216.

33. Minayo MCS. A violência social sob a perspectiva da saúde pública. Cad Saúde Pública 1994; 10: 7-18.

34. Souza ER. Homicídios no Brasil: O grande vilão da saúde pública na década de 80. Cad Saúde Pública 1994; 10: 45-60.

35. Yunes J, Rajs D. Tendencia de la mortalidad por causas violentas en la población general y entre los adolescentes y jóvenes de la Región de las Américas. Cad Saúde Pública 1994; 10: 88-125.
36. Barata RB, Ribeiro MCSA, Moraes JC. Tendência temporal da mortalidade por homicídio na cidade de São Paulo, Brasil, 19791994. Cad Saúde Pública 1999; 15: 711-718.

37. Cordeiro R, Donalisio MR. Male homicide in the Metropolitan Region of São Paulo between 1979 and 1998: a pictorial approach. Cad Saúde Pública 2001; 17: 669-677.

38. de Lima ML, de Souza ER, Ximenes R, de Albuquerque MF, Bitoun $\mathrm{J}$, Barros MD. Homicide progression per geographical area in the State of Pernambuco, Brazil, 1980-1998. Rev Saúde Pública 2002; 36: $462-469$.

39. Vermelho LL, Jorge MH. Youth mortality: analysis of the period from 1930 to 1991 (the epidemiological transition to violence). Rev Saúde Pública 1996; 30: 319-331. 


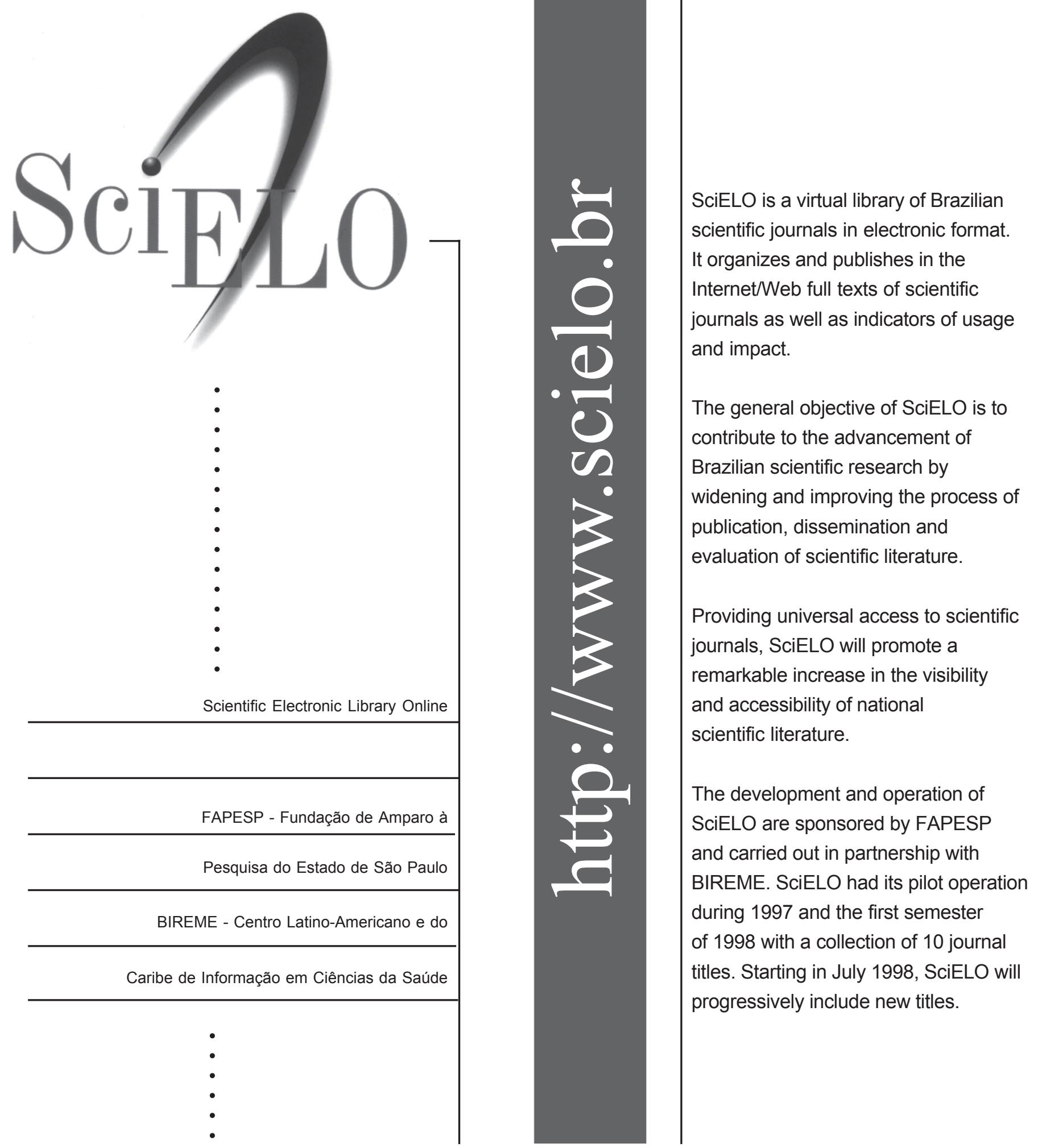

